\title{
Influence of light and shoot development stage on leaf photosynthesis and carbohydrate status during the adventitious root formation in cuttings of Corylus avellana L.
}

\author{
Sergio Tombesi ${ }^{1 *}$, Alberto Palliotti ${ }^{1}$, Stefano Poni ${ }^{2}$ and Daniela Farinelli ${ }^{1}$ \\ ${ }^{1}$ Dipartimento di Scienze Agrarie, Alimentari e Ambientali, Università di Perugia, Perugia, Italy, ${ }^{2}$ Dipartimento di Scienze delle \\ Produzioni Vegetali Sostenibili, Università Cattolica del Sacro Cuore, Piacenza, Italy
}

\section{OPEN ACCESS}

Edited by:

Jose l. Hormaza,

Instituto de Hortofruticultura Subtropical y Mediterranea la Mayora,

Spain

Reviewed by: Agostino Sorgona',

Università Mediterranea di Reggio

Calabria, Italy

Javier Rodrigo,

Centro de Investigación y Tecnología Agroalimentaria, Spain

*Correspondence:

Sergio Tombesi

sergio.tomb@gmail.com

Specialty section: This article was submitted to Crop Science and Horticulture, a section of the journal

Frontiers in Plant Science

Received: 04 August 2015 Accepted: 23 October 2015 Published: 06 November 2015

Citation:

Tombesi S, Palliotti A, Poni S and Farinelli D (2015) Influence of light and

shoot development stage on leaf photosynthesis and carbohydrate status during the adventitious root

formation in cuttings of Corylus avellana L. Front. Plant Sci. 6:973.

doi: 10.3389/fpls.2015.00973
Adventitious root formation in plant cuttings is influenced by many endogenous and environmental factors. Leaf photosynthesis during rooting of leafy cuttings in hard to root species can contribute to supply carbohydrates to the intensive metabolic processes related to adventious root formation. Light intensity during rooting is artificially kept low to decrease potential cutting desiccation, but can be limiting for photosynthetic activity. Furthermore, leafy cuttings collected from different part of the shoot can have a different ability to fuel adventitious root formation in cutting stem. The aim of this work was to determine the role of leaf photosynthesis on adventitious root formation in hazelnut (Corylus avellana L) (a hard-to-root specie) leafy cuttings and to investigate the possible influence of the shoot developmental stage on cutting rooting and survival in the post-rooting phase. Cutting rooting was closely related to carbohydrate content in cutting stems during the rooting process. Cutting carbohydrate status was positively influenced by leaf photosynthesis during rooting. Non-saturating light exposure of leafy cuttings can contribute to improve photosynthetic activity of leafy cuttings. Collection of cuttings from different part of the mother shoots influenced rooting percentage and this appear related to the different capability to concentrate soluble sugars in the cutting stem during rooting. Adventitious root formation depend on the carbohydrate accumulation at the base of the cutting. Mother shoot developmental stage and leaf photosynthesis appear pivotal factors for adventitious roots formation.

Keywords: hazelnut, soft wood cuttings, rooting, carbohydrates, light

\section{INTRODUCTION}

Adventitious root formation in plant cuttings is a complex physiological process involving plant growth substances as well as cutting water relations and nutritional status (Hartmann and Kester, 1983). The understanding of the physiological bases underlying adventitious root formation is essential for the selection of plant material to be used for cutting, the cutting preparation prior 
to rooting and choice of best environmental conditions during cutting rooting. These factors have a primary influence on rooting percentage that is crucial for economic viability of hardto-root species propagation.

Adventitious root initiation and growth is an intensive metabolic process that, promoted by auxins and/or other promoting growth regulators, lead to the increase of enzyme activity and to the synthesis of RNA and proteins (Hartmann and Kester, 1983; DeKlerk et al., 1999; Legué et al., 2014). Starch content in cutting stem decreases during root formation, providing energy, and carbon skeletons to the rooting zone and fueling root development and growth (Hartmann and Kester, 1983; Haissig, 1989; Druege et al., 2004). Cutting leaves assimilate $\mathrm{CO}_{2}$ over the whole rooting phase (Smalley et al., 1991; Yue and Margolis, 1993; Klopotek et al., 2012) even though in pea and Acer rubrum cuttings photosynthesis is limited (Davis and Potter, 1981; Smalley et al., 1991). Thus, leaf photosynthesis in leafy cuttings can play a crucial role at providing carbohydrates to root formation and growth in particular when the rooting process lasts for several weeks.

High light intensity is considered detrimental for cutting rooting because it increases leaf temperature and transpiration and facilitates leaf and cutting dehydration. In fact, high light regimes decrease cutting rooting in many woody and herbaceous species (Stoutemyer and Close, 1946; Waxman, 1965; Hansen, 1975; Loach, 1979; Loach and Gay, 1979; Grange and Loach, 1985; Aminah et al., 1997; Zaczek et al., 1997; Zobolo, 2010). On the other hand, in some other species-especially herbaceousdaily light irradiation is positively correlated with cutting rooting and development (Lopez and Runkle, 2008; Park et al., 2011; Currey et al., 2012). If carbohydrate pool of cuttings can influence cutting rooting, then sustained leaf photosynthesis could contribute to replenish or to increase cutting carbohydrate content. In greenhouses, light intensity, the main driver of leaf photosynthesis, is generally kept low (i.e., well below the light saturation point for photosynthesis) to limit leaf transpiration and heating.

Hazelnut (Corylus avellana L.) is considered a species difficult to be propagate by cutting (Hartmann and Kester, 1983). Currently, hazelnut is propagated mainly by layering, but the large number of mother plant required for layering (i.e., transmission of bacteria and viruses) make it difficult to assure the sanity of propagation material. On the other hand, hazelnut grafting is still not a common practice due to the erratic graft taking percentage and the higher cost of this propagation system as compared to layering. However, hazelnut propagation by cutting is viable, and recent studies have reported rooting percentages variable from 20 to $70 \%$ depending on the cutting treatment and the time cuttings are collected (Cristofori et al., 2010; Contessa et al., 2011). In particular, timing of cutting collection is a crucial factor for cutting rooting in hazelnut; the best period of the year is June in the north hemisphere (Cristofori et al., 2010) and January in the south hemisphere (Santelices and Palfner, 2010). Over that period of the year vegetative shoots are still growing and shoot lignification is starting to occur from the base to the apex. Earlier reports on other species have pointed out that cuttings taken from different part of the shoots (i.e., apical or basal) can have different rooting capability; for instance, blueberry (Vaccinum corimbosum L.) and Peltophorum pterocarpum cuttings taken from the basal portion of shoots rooted much better than those taken from the terminal part (O’Rourke, 1944; Saifuddin et al., 2013), whereas the opposite occurred in cherries (Prunus avium L.) (Hartmann and Brooks, 1958). Our first hypothesis was that cutting leaf photosynthetic activity under greenhouse condition is similar to that measured in the field and that a moderate increase of light availability in greenhouse could increase leaf photosynthesis in cuttings leading to an increase of carbohydrate content in leafy cuttings stimulating root formation and growth. We hypothesized that the use of mist sprays can control the water status of leaf cuttings by counterbalancing the increased temperature and the increased leaf transpiration. Furthermore, considering that in hazelnut the optimal cutting collection time is quite limited and that it coincides with active vegetative shoot growth, our second hypothesis was that the development stage of cuttings can influence their rooting capability and their subsequent survival in the post-rooting phase.

The aim of the present work was to determine the role of leaf photosynthesis on adventitious root formation in hazelnut leafy cuttings and to investigate the possible influence of the shoot developmental stage on cutting rooting and survival in the post-rooting phase.

\section{MATERIAL AND METHODS}

\section{Mother Plants}

Cuttings of Corylus avellana L cv. Tonda di Giffoni were collected in 2014 at the experimental orchard of the Department of Agricultural, Food, and Environmental Sciences of the University of Perugia located nearby Deruta, Italy $\left(42^{\circ} 58^{\prime} 21.8^{\prime \prime} \mathrm{N}\right.$, $12^{\circ} 24^{\prime} 08.7^{\prime \prime} \mathrm{E}$ ). Mother plants were 30 year old and were trained to free bush. A topping cut at $1 \mathrm{~m}$ of height was carried out during January 2014 by a disk pruning machine to stimulate emissions of vegetative suckers to be used as mother shoots. Cuttings were harvested from the vegetative shoots originated from the part immediately below the pruning cut.

\section{Gas Exchanges and Water Potential in Mother Plants}

Prior to cutting collection, photosynthetic light response curves were measured between 10 and 12 a.m. on 10 leaves per each shoot zone (i.e., basal, between node 2 and 7, apical, between node 8 and 13) using a portable open system LCA3 infrared gas analyser (ADC Bioscientific ltd., Hoddesdon, UK) equipped with a Parkinson leaf chamber $\left(11.2 \mathrm{~cm}^{2}\right.$ area). Leaves were adapted to dark for $20 \mathrm{~min}$, then gas exchange measurements started and leaves were progressively exposed to five levels of PAR by covering the leaf by a shield composed by a variable number of shading net sheets Maximum quantum yield was obtained by the slope of the regression equation of An vs. PAR at PAR values below saturation point (PAR $<500 \mu \mathrm{mol} \mathrm{m}^{-2} \mathrm{~s}^{-1}$ ) After the $\mathrm{A}_{\mathrm{n}}$ vs. PAR measurement, $\Psi_{\text {stem }}$ was measured on each mother plant $(n=5)$ on one mature leaf that had been wrapped in plastic film 
and aluminum foil $2 \mathrm{~h}$ prior to the measurements (McCutchan and Shackel, 1992) using a pressure chamber (Soilmoisture Corp, Santa Barbara, CA, USA). $\Psi_{\text {leaf }}$ was measured as previously described on other five leaves per each shoot portion after the $A_{n}$ vs. PAR measurements.

\section{Cutting Collection and Rooting Conditions}

On June 23rd shoots were cut above the second basal node, immediately placed in a container with the basal part dipped in tap water and then taken to the greenhouse facility close the orchard. At this point shoots had 12-13 nodes; shoot apices (terminal 3 nodes) were discarded, then mother shoots were cut in two segments (basal and apical part of the shoot) of about five nodes each. Single node leafy cuttings $(7-10 \mathrm{~cm}$ long) were obtained sectioning basal and apical mother shoots segments.

Cutting base was immediately dipped in $500 \mathrm{mg} \mathrm{L}^{-1}$ hydroalcoholic solution (80/20 v.v.) of Indol-Butyric Acid (IBA) for $60 \mathrm{~s}$ (Contessa et al., 2011). IBA-treated cuttings were immediately placed in a rooting bench at a density of $\sim 300$ cuttings $/ \mathrm{m}^{2}$. About 1800 cuttings (half from basal and half from apical part of mother shots) were used in the experiment. The rooting bench ( $1.20 \mathrm{~m}$ wide and $6 \mathrm{~m}$ long) was equipped with a bottom heat apparatus set at $\sim 25^{\circ} \mathrm{C}$ and a mist system. Mist nozzles were placed every $1 \mathrm{~m}$ in the center of the rooting bench. Mist duration and frequency during the daylight time was set at $15 \mathrm{~s}$ and $15 \mathrm{~min}$, respectively. Perlite was used as rooting medium.

Three different light regimes were applied during the rooting period (i.e., June 23-August 8) described as follows: Control, greenhouse light intensity $\left(\sim 100 \mu \mathrm{mol} \mathrm{m} \mathrm{m}^{-2} \mathrm{~s}^{-1}\right)$; Light + , greenhouse light intensity plus artificial lighting (Son-T Agro $400 \mathrm{~W}$, Philips, Amsterdam, NL) from 7 a.m. to 7 p.m. ( 200-300 $\mu \mathrm{mol} \mathrm{m}{ }^{-2} \mathrm{~s}^{-1}$ ); Shaded, the bench was covered with a shading net ( $\sim 30 \%$ absorbed light) placed at $30 \mathrm{~cm}$ above the cutting leaves and allowing a light intensity $\sim 30-70 \mu \mathrm{mol} \mathrm{m}^{-2}$ $\mathrm{s}^{-1}$. About 300 basal and 300 apical cuttings were subjected to each light regime.

\section{Gas Exchange and Water Potential In Cuttings}

Air temperature and relative humidity $(\mathrm{RH})$ was measured in each light treatment every $60 \mathrm{~s}$ by a temperature and humidity data logger (PCE-HT71, PCE, Italy) during all the rooting period. Air vapor pressure deficit (VPD) was calculated after Monteith and Unsworth (1990).

Stomatal conductance $\left(g_{s}\right)$ and net assimilation $\left(A_{n}\right)$ measurements were carried out between 10 and 12 a.m. every three days during the first 10 days and, hereafter, approximately every week on five leaves (i.e., five cuttings) per treatment using a portable open system LCA3 infrared gas analyser (ADC Bioscientific ltd., Hoddesdon, UK) equipped with a Parkinson leaf chamber $\left(11.2 \mathrm{~cm}^{2}\right)$. Prior measurements, cutting leaves superficies were gently soaked up by a dry paper to eventually remove free water on leaf surface. Measurements were performed under current light intensity at the timing of measurement maintaining each leaf in its current position. Cutting leaf water potential $(\Psi)$ was measured over the same days and immediately after gas exchange measurements using a pressure chamber (Soilmoisture Corp, Santa Barbara, CA, USA).

\section{Carbohydrate Determination}

Cuttings used for gas exchange $(n=5)$ and $\Psi$ measurements were immediately placed in liquid nitrogen and then stored in a freezer at $-80^{\circ} \mathrm{C}$. Then, the material was weighted and lyophilized (LIO5P, 5 Pascal, Trezzano, Italy). Lyophilized material was weighted (dry weight) and grinded (MF10, IKAlabortechnik, Staufen, Germany). Leaf material and basal portion (basal $5 \mathrm{~cm}$ ) of cutting stem $0.01 \mathrm{~g}$ of powder were placed in $15 \mathrm{ml}$ tubes and added with a solution of ethanol $80 \%$ and placed in a warm bath with temperature set at $80^{\circ} \mathrm{C}$ for $1 \mathrm{~h}$. After $10 \mathrm{~min}$ of centrifugation at $10,000 \mathrm{rpm}, 10 \mu \mathrm{l}$ of supernatant was sampled and used for the determination of alcohol soluble sugars by the Anthrone method (Morris, 1948; Loewus, 1952). For starch determination, pellet material was then washed with sodium acetate buffer and then added with $0.5 \mathrm{ml}$ of sodium acetate buffer. Tubes were placed in warm bath with temperature set at $80^{\circ} \mathrm{C}$ for $1 \mathrm{~h}$. One milliliter of solution of amyloglocosidase and $\alpha$-amylase in $0.05 \mathrm{M}$ sodium acetate buffer was added as described by Chow and Landhäusser (2004) and bath temperature was set at $50^{\circ} \mathrm{C}$. Sugar content was then measured on the supernatant by the anthrone method as previously described

\section{Cutting Rooting Assessment and Post-rooting Cares}

Rooting was assessed two times during the experiment: July 15 [Day of the year (DOY) 194] and August 8 (DOY 214). At DOY 194 cuttings were separated in dead (blackened and rot cuttings), still (without any visual symptom of rooting), callused (with callus on the basal part of the stem), and rooted (with at least one visible root) in order to assess if the treatments had effect on the speed of adventitious root formation. At the end of the experiment cuttings were reclassified in dead, poorly rooted (sum of total root length shorter than $10 \mathrm{~cm}$ ), well-rooted (sum of total root length longer or equal to $10 \mathrm{~cm}$ ).

On August 8, after rooting assessment, cuttings were transferred in $4 \mathrm{~L}$ pots filled with a mixture of peat:pozzolana (50:50 v.v.) and taken back to the greenhouse under a light regime similar to that of the control treatment. Cuttings were tagged and divided in different light treatments, cutting types (apical, basal) and rooting quality (well and poorly rooted). Pots were placed on another bench equipped with a mist system. Mist duration and frequency during the daylight time was set to $15 \mathrm{~s}$ and $60 \mathrm{~min}$, respectively to prevent leaf desiccation (Fordham et al., 2001) and plant mortality was assessed on March 31, 2015 after sprouting in order to evaluate the possible economic impact of the tested techniques.

\section{Statistical Analysis}

Statistical analysis was performed using linear and non-linear regression analysis to assess the correlation between PAR and $A_{n}$ and the correlation between carbohydrates and rooting percentage using Sigmaplot 8.0 (Systat Software Inc., San Jose, CA, USA) and $\mathrm{R}^{2}$ significance was assessed by ANOVA. 
Treatments were analyzed by One-way ANOVA with significance level set at 0.05 ; means were separated by Tukey's w-procedure at $P=0.05$. Relative frequencies were analyzed by $\chi^{2}$-test. $P$-value was set at 0.05 .

\section{RESULTS}

Light + treatment caused an increase of air temperature of about $2{ }^{\circ} \mathrm{C}$ in the first afternoon in comparison with other two treatments (Figure 1). RH was lower in Light+ treatment of about $10 \%$ points than in other two treatments. Differences in air temperature and $\mathrm{RH}$ resulted in $\mathrm{V}_{\text {air }}$ increase between 0.4 and 0.5 $\mathrm{KPa}$ in the Light + treatment in comparison with the other two treatments during the afternoon.

Photosynthetic light-response curve in the field was significantly different between basal and apical shoot leaves (Figure 2) as the latter had higher $\mathrm{A}_{\mathrm{n}}$ at saturating light (basal $7.92 \pm 0.65 \mu \mathrm{mol} \mathrm{CO} \mathrm{m}^{-2} \mathrm{~s}^{-1}$, apical $9.85 \pm 0.95 \mu \mathrm{mol} \mathrm{CO}$ $\mathrm{m}^{-2} \mathrm{~s}^{-1}$ ). Than basal shoot leaves (mean $\mathrm{A}_{\mathrm{n}}$ at saturating light $\left(\mathrm{PAR}>500 \mu \mathrm{mol}\right.$ photons $\mathrm{m}^{-2} \mathrm{~s}^{-1}$ ) was compared by $t$-test $P<0.01)$. Quantum yield $(\Phi)$ was significantly lower in basal shoot leaves than in apical shoot leaves (apical $\Phi=0.025 \mu \mathrm{mol}$ $\mathrm{CO}_{2} \mu \mathrm{mol}$ photons ${ }^{-1}$; basal $\Phi=0.013 \mu \mathrm{mol} \mathrm{CO}_{2} \mu \mathrm{mol}$ photons $^{-1}$ ) (Figure 3). $A_{n}$ measured in cuttings collected from shoot apical and basal parts (Figures $3 \mathbf{A}, \mathbf{B}$, respectively) was correlated with PAR (apical $R^{2}=0.77 P<0.001$; basal $R^{2}=0.69 P<0.001$ ). Regressions slope of $\mathrm{A}_{\mathrm{n}}$ vs. PAR measured in greenhouse during rooting was similar to that measured in the field prior cutting collection (test for homogeneity of regression apical $P=0.42$, basal $P=0.44$ ).

Shaded cuttings had higher $\Psi$ while Light + had the lowest $\Psi$ values throughout the experiment in both apical and basal portions (Figure 4). Control cuttings had $\Psi$ values in between the other two treatments. However, apical cutting $\Psi$ values measured during the rooting were consistently higher than leaf water potential measured in the field prior cutting collection. In basal cuttings the difference between cutting $\Psi$ and $\Psi_{\text {leaf }}$ was less marked, although cutting $\Psi$ was never below the $\Psi_{\text {leaf }}$ during rooting.

Stomatal conductance $\left(\mathrm{g}_{\mathrm{s}}\right)$ increased over the whole rooting period in all treatments in basal as well as in apical cuttings (Figure 5). Moreover, $g_{s}$ started to increase right after cuttings were placed in greenhouse. At the end of the experiment Light+ rooted cuttings had higher $g_{s}$ than Shaded cuttings in basal and apical cuttings. Control cuttings had $\mathrm{g}_{\mathrm{s}}$ value in between those of Light+ and Shaded cuttings.

Leaf non-structural carbohydrates (NSC) content in apical cutting leaves slightly decreased in the first week after cutting collection in Light + and control apical cuttings (Figure 6). After the first week, NSC in leaves of cuttings collected from the apical part of the shoot of Control and Shaded treatment was almost steady up to DOY 210. In the last sampling at DOY 214, NSC decreased in all three treatments. Opposite to the pattern of the other two treatments, in Light+ cuttings collected from the apical part of the shoot, leaf NSC content increased up to DOY 184 and thereafter decreased up to the end of rooting period. NSC pattern in all treatment reflected that of

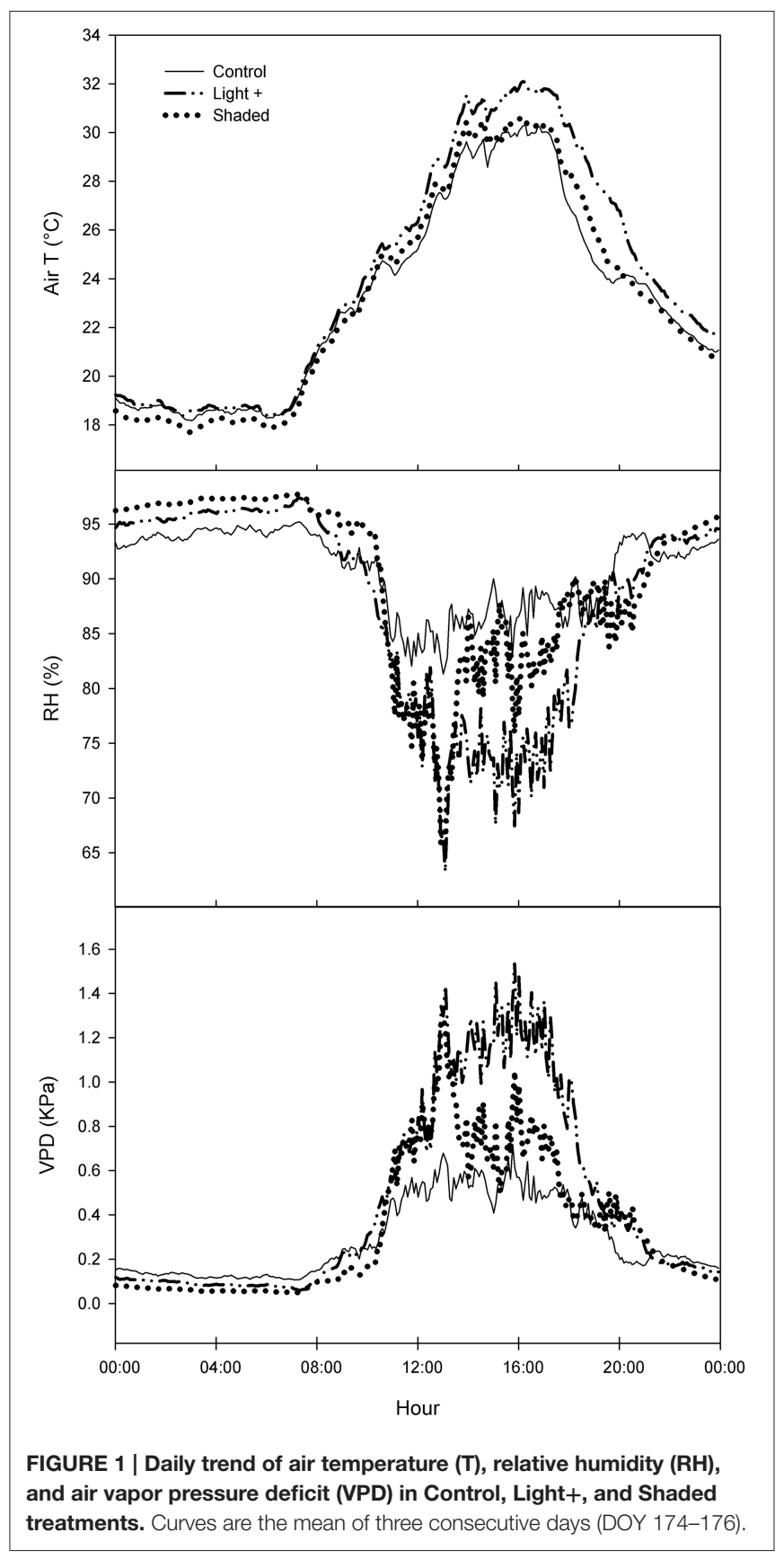

soluble sugars because during the whole experiment leaf starch content remained almost constant except for DOY 183 when Light+ leaves had a significant higher starch content than other two treatments and original content at cutting collection date (Figures 6B,C). In cuttings collected from the basal part of the shoot, leaf NSC content increased during the first 10 days in the Light + treatment (Figure 6D). In Control treatments, leaf NSC was stable across the same period and in Shaded treatment leaf NSC content decreased. At DOY 183 leaf NSC content rapidly decreased in Light+ treatment and remained almost steady up to the end of the experiment even if during this time span leaf NSC showed a slightly decreasing trend. After DOY 183, 


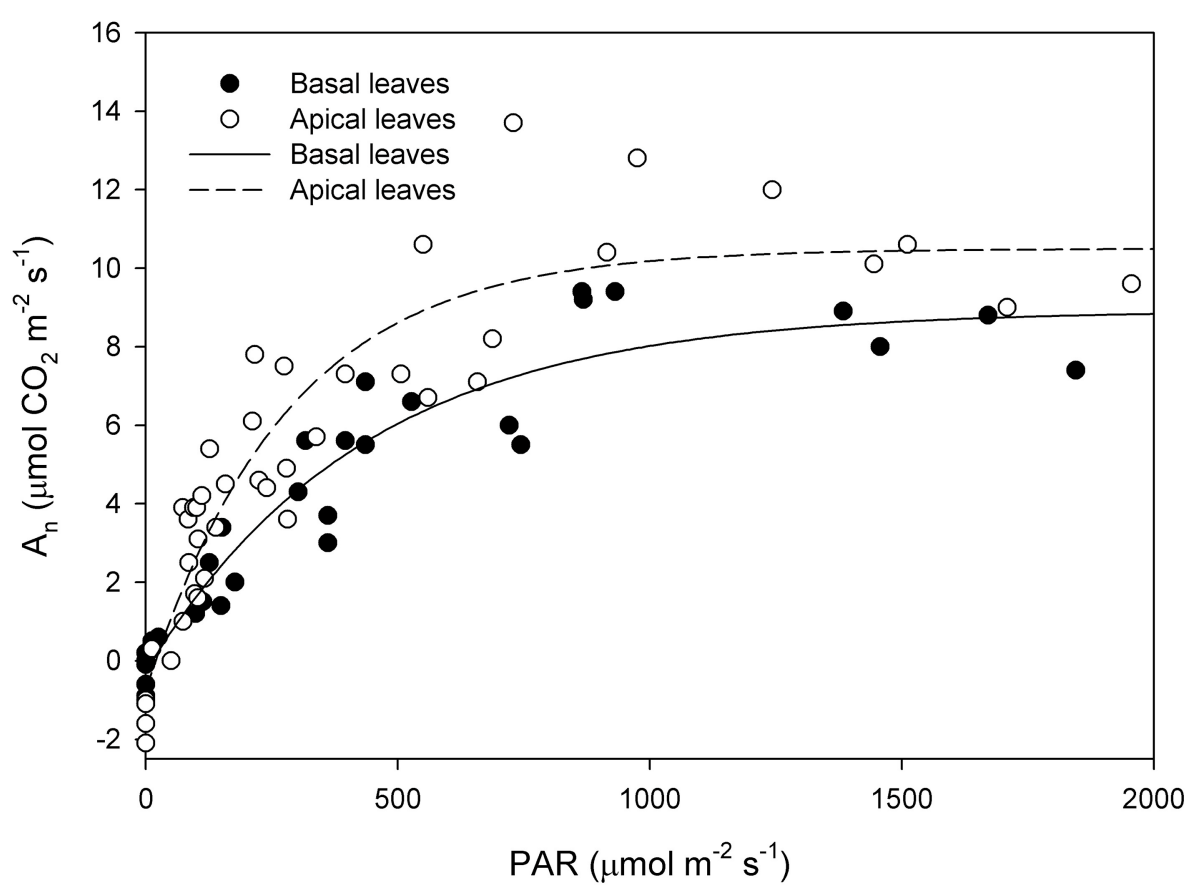

FIGURE 2 | Net $\mathrm{CO}_{2}$ assimilation ( $\left.A_{n}\right)$ vs. Photosynthetic Active Radiation (PAR) in basal and apical shoot leaves measured in the field on the collecting date. [basal leaves $y=-0.28+9.2\left(1-\mathrm{e}^{-0.002 x}\right) R^{2}=0.92 P<0.001$; apical leaves $y=-0.78+11.27\left(1-\mathrm{e}^{-0.003 x}\right) R^{2}=0.87 P<0.001$ ].

Control cuttings collected from the basal part of the shoot had a NSC content in leaves similar to that of Light+ cuttings. On the other hand, Shaded cuttings collected from the basal part of the shoot, even though with some fluctuations, maintained an almost steady level of NSC from DOY 179 up to the end of the experiment. As for the cuttings collected from the apical part of the shoot, also in cuttings collected from the basal part of the shoot, NSC pattern in leaves was mainly the results of soluble sugar variation (Figure 6E). Leaf starch was almost steady all over the experiment even though Light+ basal leaves had higher starch content than other two treatments from DOY 174 up to DOY 210 (Figure 6F). At DOY 174, 179, and 201 leaf starch content in light + treatment was higher than that measured at cutting collection.

Stem NSC of cuttings collected from the apical part of the shoot increased in Light + treatment until DOY 183, while in the same period it remained almost steady in Control treatment and decreased in Shaded treatment (Figure 7A). Thereafter, NSC content in stems decreased until the end of the experiment in apical cuttings of all treatments; Light + and Control treatment kept a NSC content greater than Shaded treatment over the whole experiment. NSC pattern was mainly influenced by soluble sugars that had the same pattern described for NSC (Figure 7B). Starch varied little during the experiment even thought at the end it was significantly lower than the initial content in all three treatments (Figure 7C). Until DOY 179, stem NSC of basal cuttings was unchanged in Light + treatment, while in the Control and Shaded treatment it decreased until DOY 183 (Figure 7D). Thereafter, NSC in Light+ and in Shaded treatment was almost unchanged until DOY 201 and then decreased again until the end of the experiment. In control treatment NSC decreased from DOY 183 until DOY 201. Generally speaking, Light+ treatment had greater NSC content than Control and Shaded cuttings, respectively, over the experiment. Soluble sugar content in stem of basal cutting was unchanged over the experiment in the Light + and control treatments (Figure 7E) on the other hand soluble sugars decreased during the experiment in shaded treatment. Starch content decreased in all treatment of about $80 \%$ in the first 12 days since cutting collection (Figure 7F). Thereafter, starch content was almost unchanged until the end of the experiment (DOY 214).

After 22 days from cutting collection the large majority of cuttings were rooted or callused (Table 1).The Shaded treatment had the highest fraction of dead cuttings, whereas Light+ treatment showed the largest percentages of rooted and callused cuttings. Basal cuttings of the control treatment had the largest percentage of still cuttings followed by Shaded treatment cuttings. After 42 days from cutting collection, at the end of the experiment (DOY 214) light + treatment had the highest percentage of rooted cuttings followed by Control and Shaded treatment, respectively (Table 2). Shaded treatment had the largest percentage of dead cuttings. Light + had the highest percentage of wellrooted cuttings while in shaded treatment about half of the rooted cuttings had poor root formation and growth. In all treatments, cuttings from the apical part of the shoots showed better rooting than cuttings collected form the shoot apical part. Final rooting percentage was linearly correlated with the mean content of NSC and soluble sugars in the stem during the experiment $\left(R^{2}=0.95\right.$ $P<0.001, R^{2}=0.94 P<0.001$, respectively) (Figures 8A,B). On the other hand final rooting percentage was not correlated 


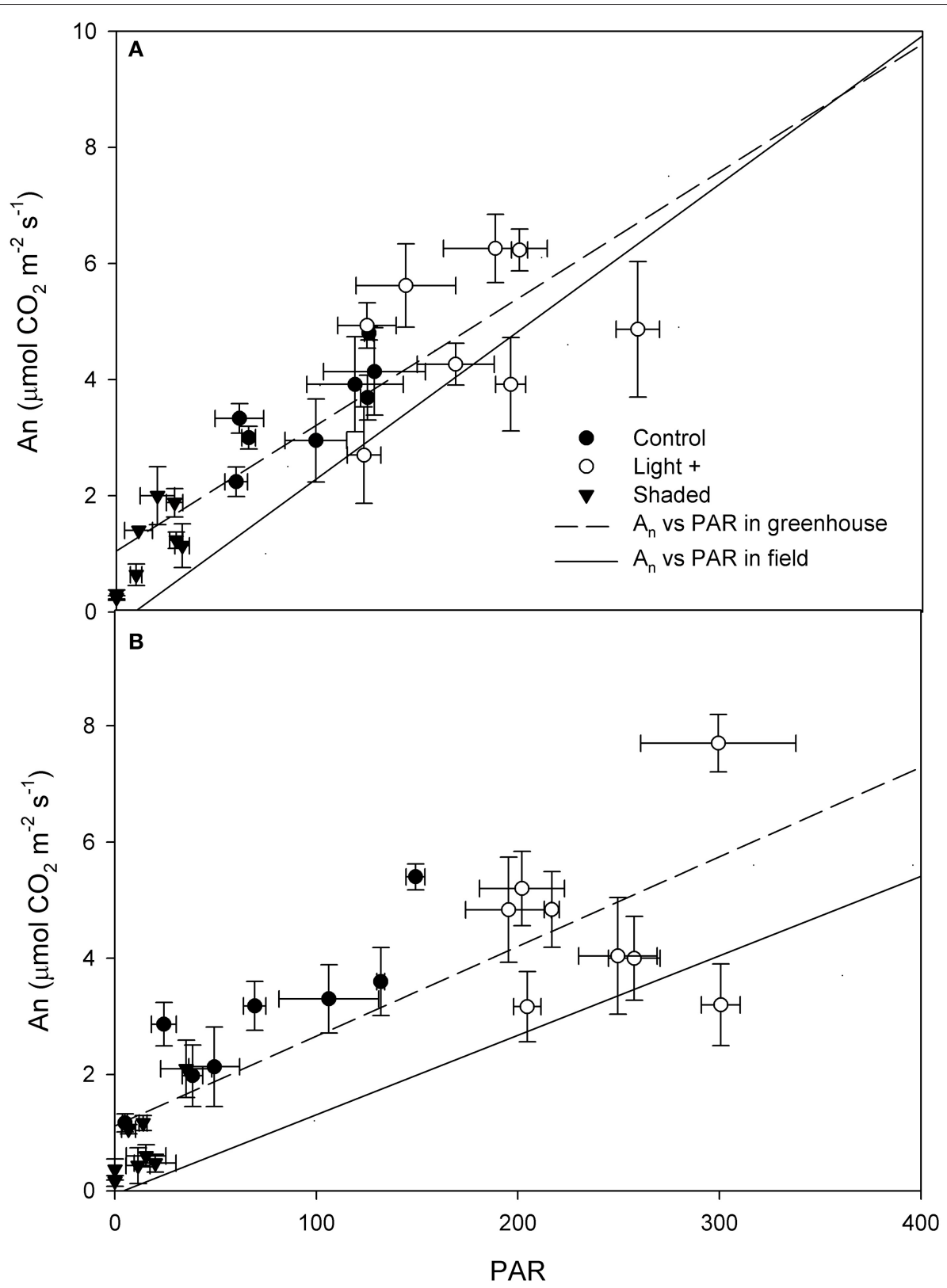

FIGURE 3 | Net assimilation $\left(A_{n}\right)$ vs. PAR measured on cutting leaves collected from the shoot apical part (A) and basal part (B) during the rooting period in the greenhouse. Dashed line represent the linear regression (apical $y=0.02 x+1.05$, basal $y=0.015 x+1.11$ ) of measurements carried out in greenhouse over the rooting period (DOY 172-214). Solid line represent the regression (apical $y=0.025 x-0.22$, basal $y=0.013 x-0.055$ ) of measurements carried out on mother plants in field prior cutting collection. Each point is the mean of five leaves $\pm S E$.

with mean content of starch in the cutting stem during the experiment $\left(R^{2}=0.21 P=0.36\right)$ (Figure $8 \mathrm{C}$ ).

The highest post-rooting plant mortality occurred in plants of the Shaded treatment followed by those from Control and Light + treatment, respectively (Table 3). In all three treatments, basal cuttings had larger mortality than apical cuttings. Plant mortality was larger in poorly rooted cuttings than in well-rooted cuttings in all treatments and independently by the portion of mother shoot from which cutting was collected.

\section{DISCUSSION}

Environmental conditions in the rooting bench where leafy cuttings are rooted are crucial for successful rooting In particular, leaf temperature and air VPD play a pivotal role in leaf survival and activity (Hartmann and Kester, 1983). In our experiment, the rooting bench was equipped with a mist apparatus that cooled leaves and decreased air VPD. All treatments were subjected to the same frequency of mist spray and as consequence of the 


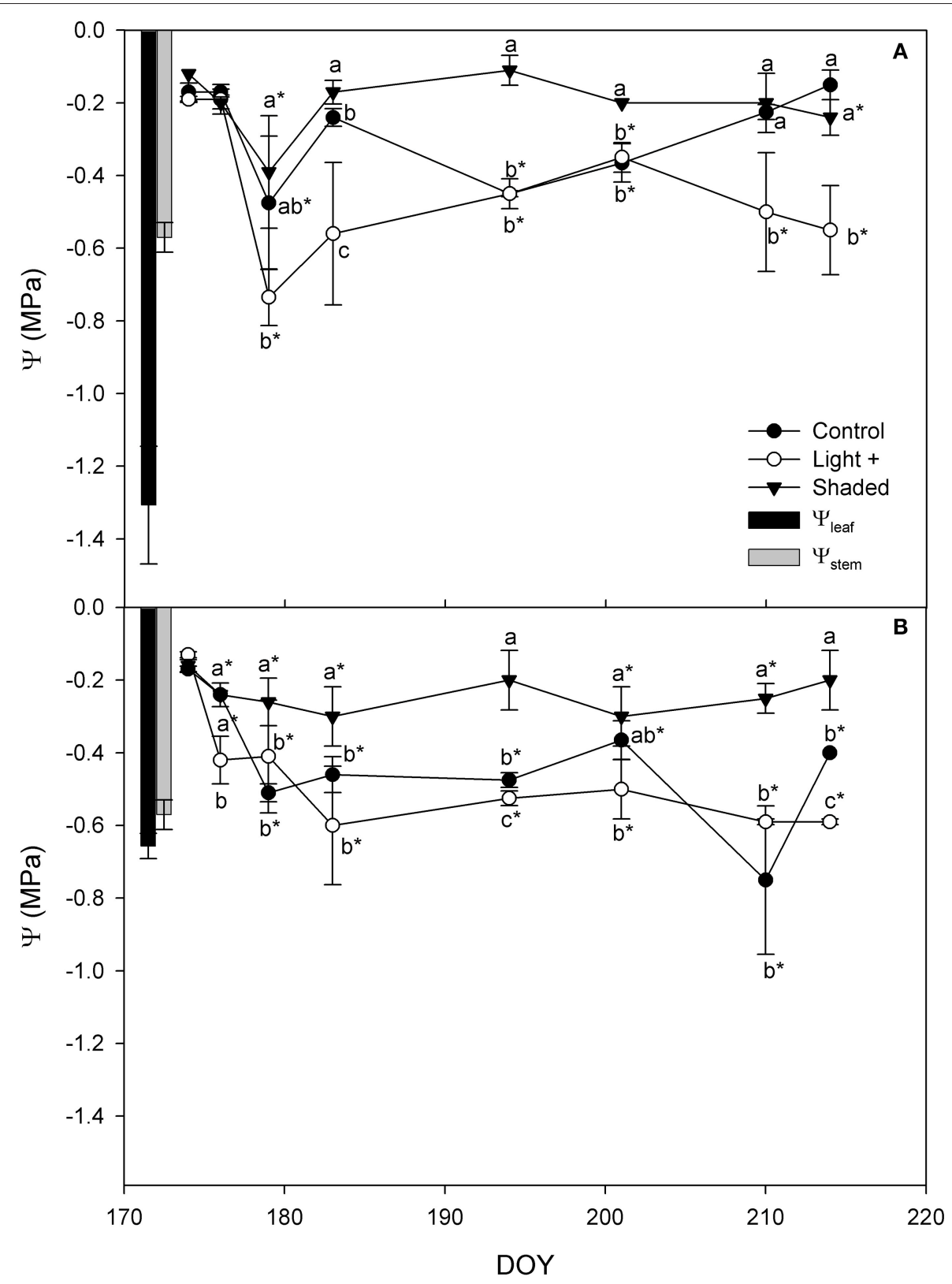

FIGURE 4 | Cutting water potential in Control, Light+, and Shaded cuttings collected from the shoot apical part (A) and basal part (B) during the rooting period in the greenhouse. Columns depict $\Psi_{\text {stem }}$ and $\Psi_{\text {leaf }}$ measured in the field on mother plants in the cutting collection day at 12 a.m. Each point is the mean of five leaves \pm SE. Points of the same sampling date with different letters are different per $P=0.05$ (Tukey test). Point marked with asterisk are different from the value measured on the cutting collection day per $P=0.05$ (Tukey test).

different light regimes at which leafy cuttings were exposed, air temperature, $\mathrm{RH}$, and air VPD varied depending on the treatment (Figure 1). In particular, in Light + , temperature increased and $\mathrm{RH}$ decreased in comparison with other two treatments resulting in higher values of air VPD that, in Light+, doubled as compared to the other two treatments. In theory, such environmental conditions are expected to be detrimental for cutting rooting, yet in our experiment we did not observe any increase of cutting mortality (Tables 1,2 ) nor any decrease of leaf photosynthesis or stomatal conductance in Light + cuttings in comparison with other two treatments.

During the experiment, water potential was consistently lower in Light + cuttings than in Shaded cuttings. Cutting water potential was similar or even higher than that measured in the field prior cutting collection and stomatal conductance increased under greenhouse conditions. These data indicate that the environmental conditions imposed at cutting rooting period were adequate for leaf and cutting survival and that the used 


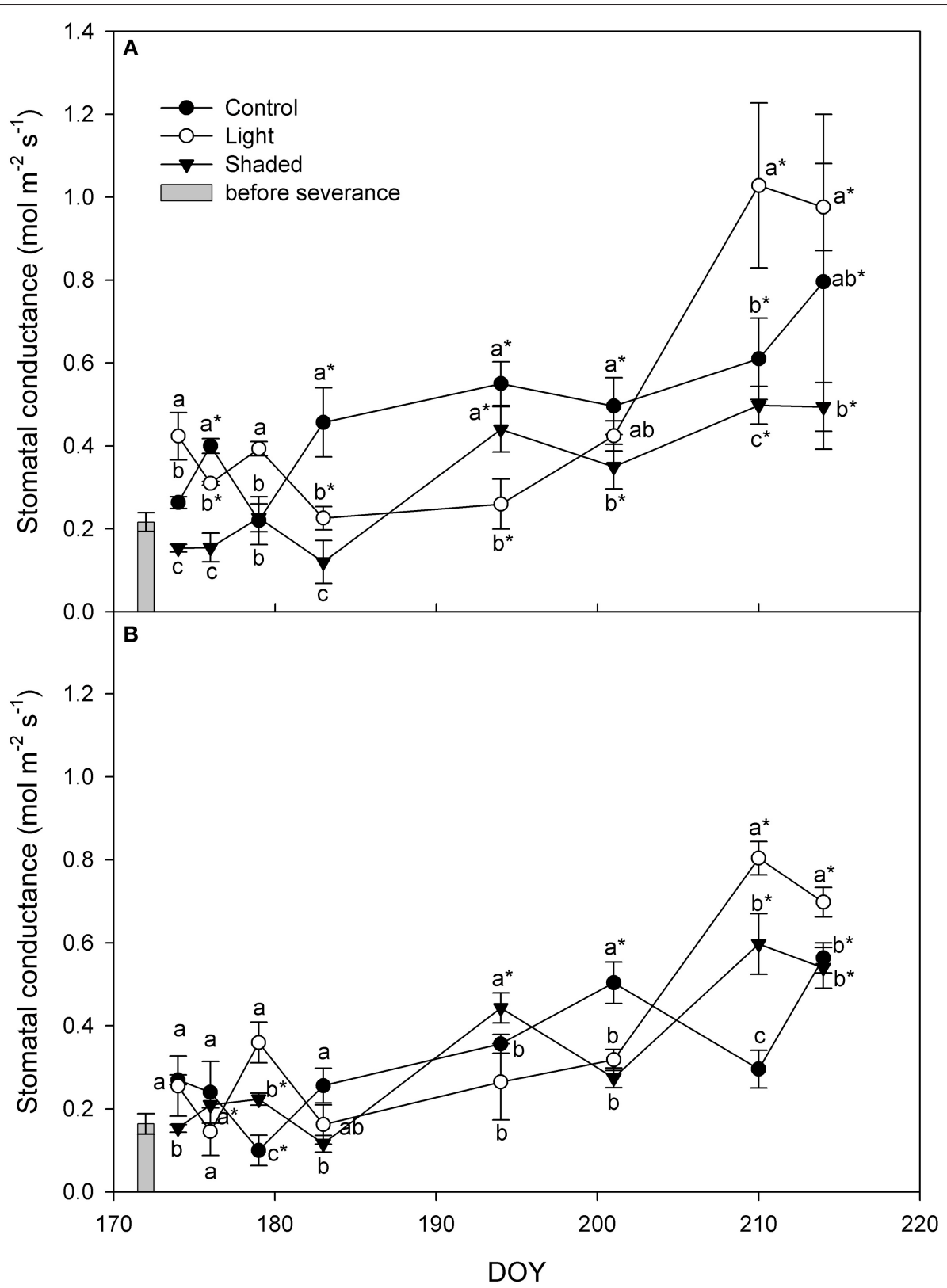

FIGURE 5 | Leaf stomatal conductance $\left(g_{s}\right)$ in Control, Light+, and Shaded cuttings collected from the shoot apical part (A) and basal part (B) during the rooting period in the greenhouse. Columns depict $g_{s}$ measured in the field on mother plants in the cutting collection day at 12 a.m. Each point is the mean of five leaves \pm SE. Points of the same sampling date with different letters are different per $P=0.05$ (Tukey test). Point marked with asterisk are different from the value measured on the cutting collection day per $P=0.05$ (Tukey test).

light regimes had a moderate effect on potential desiccation of hazelnut leafy cuttings.

Light saturation point measured in leaves prior cutting collection was around $500 \mu \mathrm{mol}$ photons $\mathrm{m}^{-2} \mathrm{~s}^{-1}$ while maximum PAR during rooting was around $300 \mu \mathrm{mol}$ photons $\mathrm{m}^{-2} \mathrm{~s}^{-1}$; at this and below this light intensity, photosynthetic efficiency was linearly correlated to PAR under field condition. In our experiment, leaf photosynthesis was linearly correlated with measured PAR. Cutting leaf photosynthesis was generally above or similar to that measured in the field prior cutting collection at similar PAR levels. Contrary to previous report on Acer rubrum, Euforbia pulcherrima and Pinus contorta (Smalley et al., 1991; Svenson et al., 1995; Brinker et al., 2004), our data suggest that in hazelnut cuttings leaf photosynthesis was not feedback down-regulated by carbohydrate accumulation in the leaf, and confirm the positive effect of environmental conditions (in particular low air VPD) on leaf photosynthesis. 


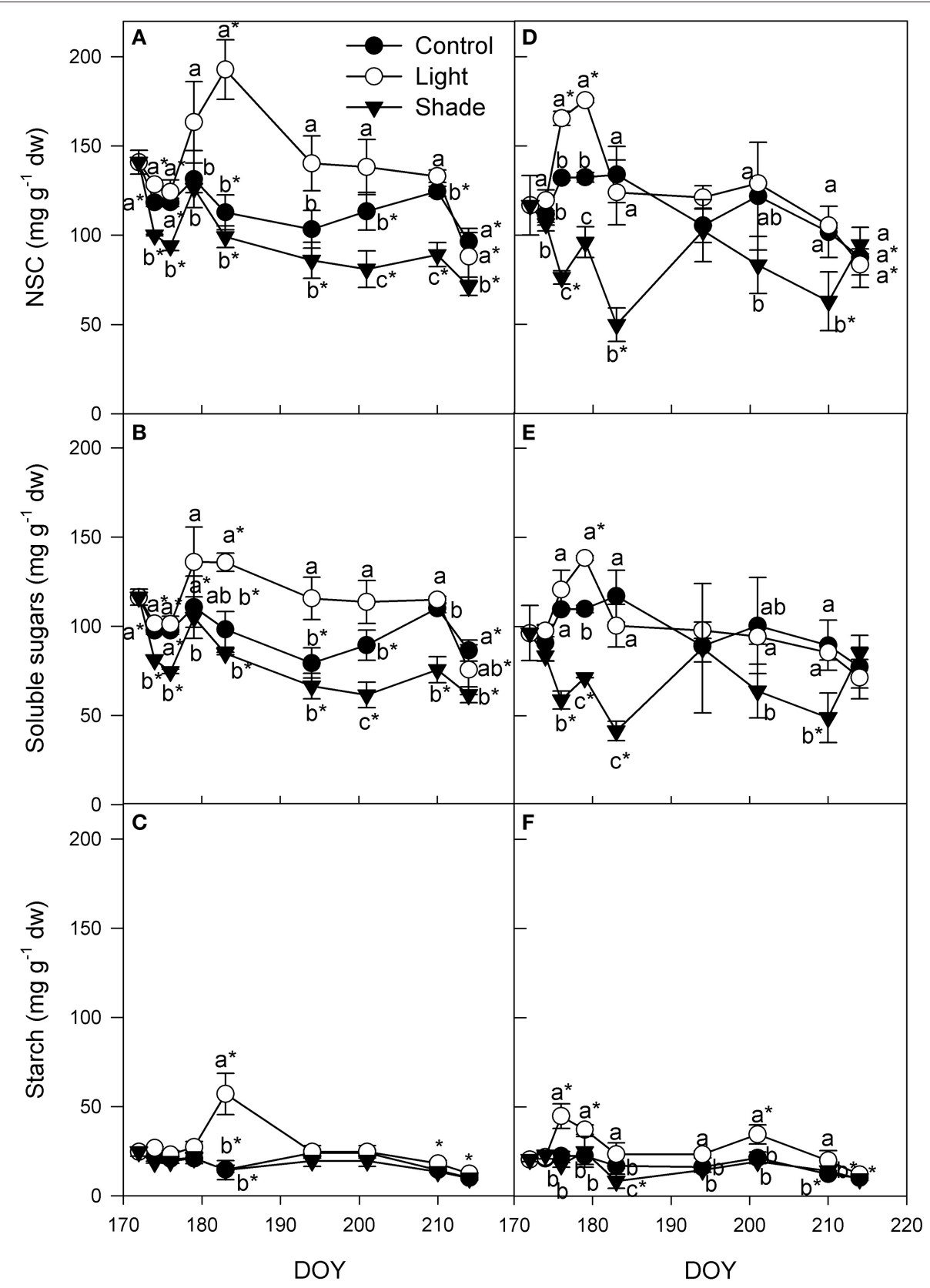

FIGURE 6 | Non-structural carbohydrates (NSC), soluble sugars and starch in leaves of cuttings collected from shoot apical part (A,B,C) and basal part (D,E,F). Each point is the mean of five leaves \pm SE. Points of the same sampling date with different letters are different per $P=0.05$ (Tukey test). Points without letters were similar per $P=0.05$. Point marked with asterisk are different from the value measured on the cutting collection day per $P=0.05$ (Tukey test).

Although cuttings collected from the apical part and basal part of the shoot had similar reaction to different light regimes during the experiment, apical cutting leaves had higher photosynthetic activity than leaves of basal cuttings. Furthermore, the increase of stomatal conductance over the rooting period was more marked in apical leaves than in basal leaves. These data suggest that apical leaves are more capable to supply carbohydrates to rooting cuttings than basal leaves. Apical leaves, developed at higher light intensity and slightly later than basal leaves, could be more photosyntetically efficient. These data are consistent with the larger stomatal conductance increase observed under low VPD in Corylus maxima full expanded leaves in comparison with younger leaves (Fordham et al., 2001). However, cutting mortality after rooting was consistently lower in apical cuttings than in basal cuttings (Table 3), indicating that reduced stomatal regulation was successfully counterbalanced by the acclimation technique used in the experiment. 


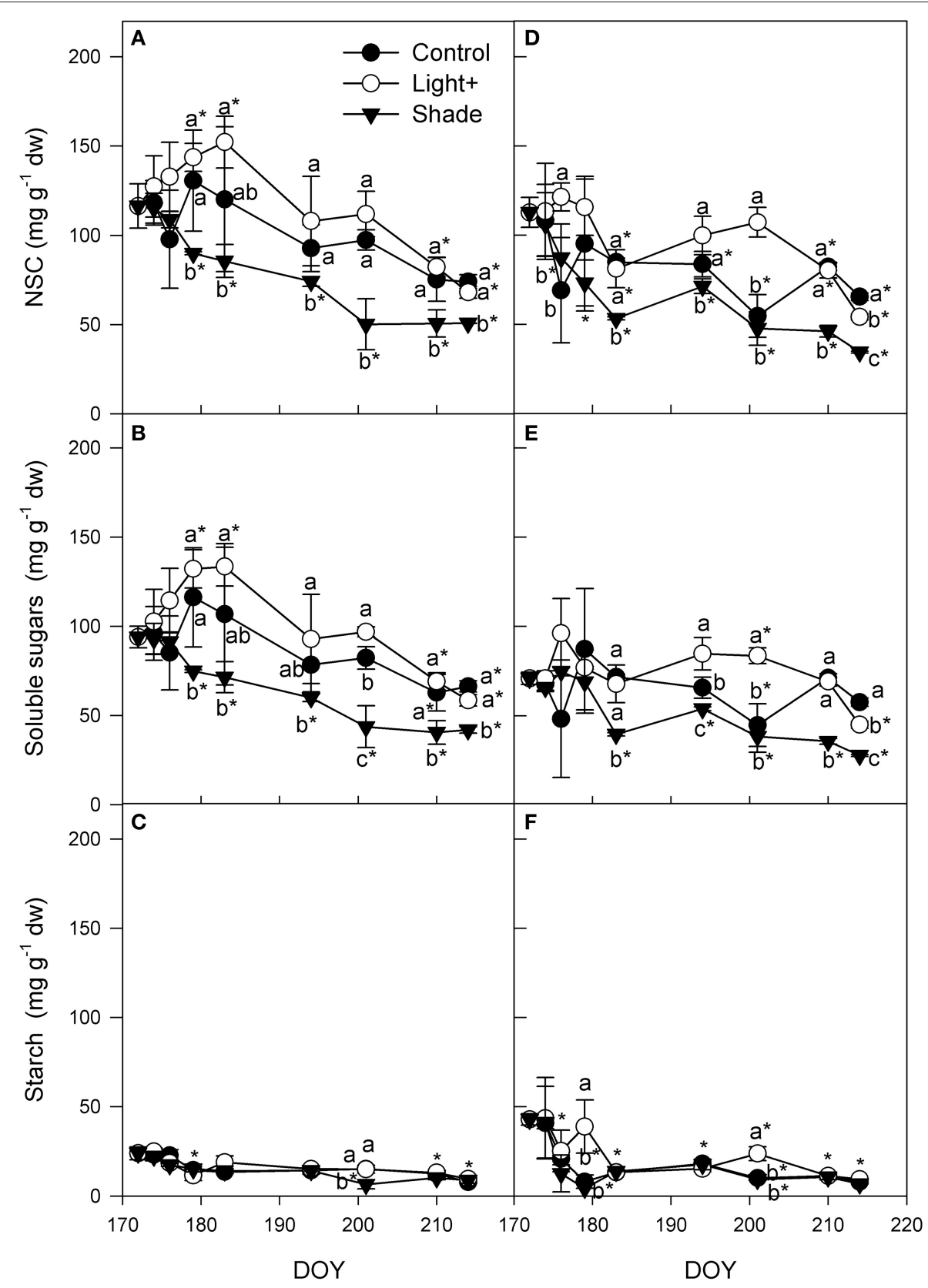

FIGURE 7 | Non structural carbohydrates (NSC), soluble sugars and starch in stems of cuttings collected from shoot apical part (A,B,C) and basal part (D,E,F). Each point is the mean of five stems \pm SE. Points of the same sampling date with different letters are different per $P=0.05$ (Tukey test). Points without letters were similar per $P=0.05$. Point marked with asterisk are different from the value measured on the cutting collection day per $P=0.05$ (Tukey test).

The rooting process is a high demanding carbohydrates process and in our experiment the carbohydrate content in cuttings showed an overall decrease during the rooting process. The decrease was more evident in cutting stems, where intense metabolic processes related with root differentiation and growth occurs, rather than in cutting leaves (Figures 6, 7).

The increase of leaf photosynthetic activity, prompted by higher light intensity, caused an increase of NSC in leaves and, to a lesser extent, in stem base up to root formation (rooting occurred between DOY 183 and 194). After root formation, NSC in leaves and particularly in stems, constantly decreased confirming that root formation and elongation is a highly expensive process in the cutting carbon budget. These data also suggest that the first part of rooting process is less expensive for cuttings in terms of NSC. However, the poor photosynthetic activity measured in Shaded cuttings appeared to be not sufficient preserve NSC content in cuttings: in the first week from cutting collection, when callusing and rooting was 
TABLE 1 | Relative frequencies of cuttings dead, still, callused and rooted at DOY 194 (22 days after cutting collection) in the three treatments.

\begin{tabular}{|c|c|c|c|c|c|c|c|c|c|c|c|}
\hline \multirow{2}{*}{$\begin{array}{l}\text { Treatment } \\
\text { Control }\end{array}$} & \multirow{2}{*}{$\begin{array}{l}\text { Cutting type } \\
\text { Apical }\end{array}$} & \multicolumn{2}{|c|}{ Dead } & \multicolumn{2}{|c|}{ Still cuttings } & \multicolumn{2}{|c|}{ Callused } & \multicolumn{2}{|c|}{ Rooted } & \multicolumn{2}{|c|}{ Callused + Rooted } \\
\hline & & $8.0 \%$ & e & $27.1 \%$ & $d$ & $33.5 \%$ & $c$ & $31.4 \%$ & $\mathrm{~b}$ & $64.9 \%$ & C \\
\hline & Basal & $10.9 \%$ & C & $41.8 \%$ & $a$ & $22.4 \%$ & e & $24.8 \%$ & C & $47.3 \%$ & d \\
\hline \multirow[t]{2}{*}{ Light + } & Apical & $4.1 \%$ & $f$ & $4.5 \%$ & e & $43.5 \%$ & $b$ & $47.9 \%$ & a & $91.4 \%$ & a \\
\hline & Basal & $22.3 \%$ & $d$ & $3.2 \%$ & e & $47.9 \%$ & $a$ & $26.6 \%$ & C & $74.5 \%$ & $b$ \\
\hline \multirow[t]{2}{*}{ Shaded } & Apical & $25.4 \%$ & $b$ & $30.4 \%$ & $\mathrm{C}$ & $26.4 \%$ & $d$ & $17.7 \%$ & $d$ & $44.1 \%$ & d \\
\hline & Basal & $39.7 \%$ & $a$ & $36.3 \%$ & $\mathrm{~b}$ & $15.0 \%$ & $f$ & $9.0 \%$ & $\mathrm{e}$ & $24.0 \%$ & e \\
\hline
\end{tabular}

Relative frequencies with different letters in each column are different per $P=0.05$ ( $\chi^{2}$-test).

TABLE 2 | Relative frequencies of cuttings dead, poorly and well-rooted at the end of the experiment (DOY 214 ) after 42 days from cutting collection in the three treatments.

\begin{tabular}{|c|c|c|c|c|c|c|c|c|c|c|c|}
\hline \multirow{2}{*}{$\begin{array}{l}\text { Treatment } \\
\text { Control }\end{array}$} & \multirow{2}{*}{$\begin{array}{l}\text { Cutting type } \\
\text { Apical }\end{array}$} & \multicolumn{2}{|c|}{ Dead } & \multicolumn{2}{|c|}{ Poorly rooted } & \multicolumn{2}{|c|}{ Well-rooted } & \multicolumn{4}{|c|}{ Total cuttings rooted } \\
\hline & & $19.7 \%$ & e & $21.3 \%$ & $\mathrm{~b}$ & $59.0 \%$ & $b$ & $80.3 \%$ & $b$ & $74.5 \%$ & $b$ \\
\hline & Basal & $32.1 \%$ & C & $13.3 \%$ & $d$ & $54.5 \%$ & $b$ & $67.9 \%$ & $\mathrm{C}$ & & \\
\hline \multirow[t]{2}{*}{ Light+ } & Apical & $7.9 \%$ & $f$ & $9.6 \%$ & e & $82.5 \%$ & $\mathrm{a}$ & $92.1 \%$ & a & $85.2 \%$ & a \\
\hline & Basal & $25.5 \%$ & $d$ & $26.1 \%$ & a & $48.4 \%$ & C & $74.5 \%$ & $b$ & & \\
\hline \multirow[t]{2}{*}{ Shaded } & Apical & $53.8 \%$ & $\mathrm{~b}$ & $16.7 \%$ & C & $29.4 \%$ & $d$ & $46.2 \%$ & $d$ & $39.4 \%$ & C \\
\hline & Basal & $68.2 \%$ & $a$ & $16.9 \%$ & C & $15.0 \%$ & e & $31.8 \%$ & e & & \\
\hline
\end{tabular}

Relative frequencies with different letters are different per $P=0.05\left(\chi^{2}\right.$-test).

still not detectable, NSC in Shaded cuttings decreased whereas in cuttings of the other treatments NSC content increased. Apical and basal cuttings followed approximately the same NSC pattern during rooting but with two major differences; although the spectacular increase $(+42 \%)$ of NSC in Light + leaves of basal cuttings was similar to that of apical cuttings subjected to the same light treatment, NSC in basal cutting stems did not increase. During the first 10 days after cutting collection, NSC remained steady even if starch decreased by $80 \%$ in the stem itself. The different pattern observed in cuttings collected from the basal and apical part of the shoot may suggest a different translocation rate of carbohydrates from leaves down to the basal part of the cutting stem: stems of basal cuttings did not reached the peak NSC level measured in stems of apical cuttings prior to rooting though NSC level in leaves was similar in basal and apical cuttings. Noteworthy, the percentage of cuttings callused or rooted after 22 days (at DOY 194) was almost equal to that of rooted in Light + and Shaded treatments. In these two treatments the large variation of NSC between treatments appear to have played a pivotal role promoting or inhibiting adventitious root formation in the Light + and in the Shaded treatment, respectively. The relatively lower NSC content, and in particular soluble sugar content, in stems of basal cuttings was in agreement with the consistent lower rooting recorded in stems of basal cuttings. Indeed, cutting rooting was linearly correlated with mean soluble sugar content in stems during rooting. These results suggest that once the hormonal promotion of adventitious rooting effectively occurred, cutting rooting in hazelnut is mainly driven by sugar availability in cutting stems. Thus, in hazelnut cutting leaf photosynthesis is an important factor during root initiation contrary to what generally reported in literature about photosynthesis and adventitious rooting (Davis, 1988).

Overall, the larger availability of NSC in stems had a positive effect on rooting quality and not just on rooting percentage; Light + and Control cuttings had consistently more well-rooted cuttings than Shaded cuttings. Though, Light + cuttings had consistently more NSC content than the other two treatments in the first week of the experiment, at the end of the experiment NSC content was similar across treatment; this can be explained as the effect of more root biomass grew in Light + cuttings than in other treatments. Improved rooting quality in Light + and Control treatments resulted in lower mortality in the postrooting period. These results underline the importance of rooting biomass development for successful survival of rooted cutting that in hazelnut represent a critical point for economic viability of propagation by cuttings.

These results contribute to explain the contrasting effect of light intensities observed in many species in previous studies (Stoutemyer and Close, 1946; Waxman, 1965; Hansen, 1975; Loach, 1979; Loach and Gay, 1979; Grange and Loach, 1985; Aminah et al., 1997; Zaczek et al., 1997; Lopez and Runkle, 2008; Zobolo, 2010; Park et al., 2011; Currey et al., 2012). Light regimes below light saturation point can enhance photosynthetic activity of leafy cutting; however, excessive light regimes (above light saturation point for photosynthesis) can increase VPD and 


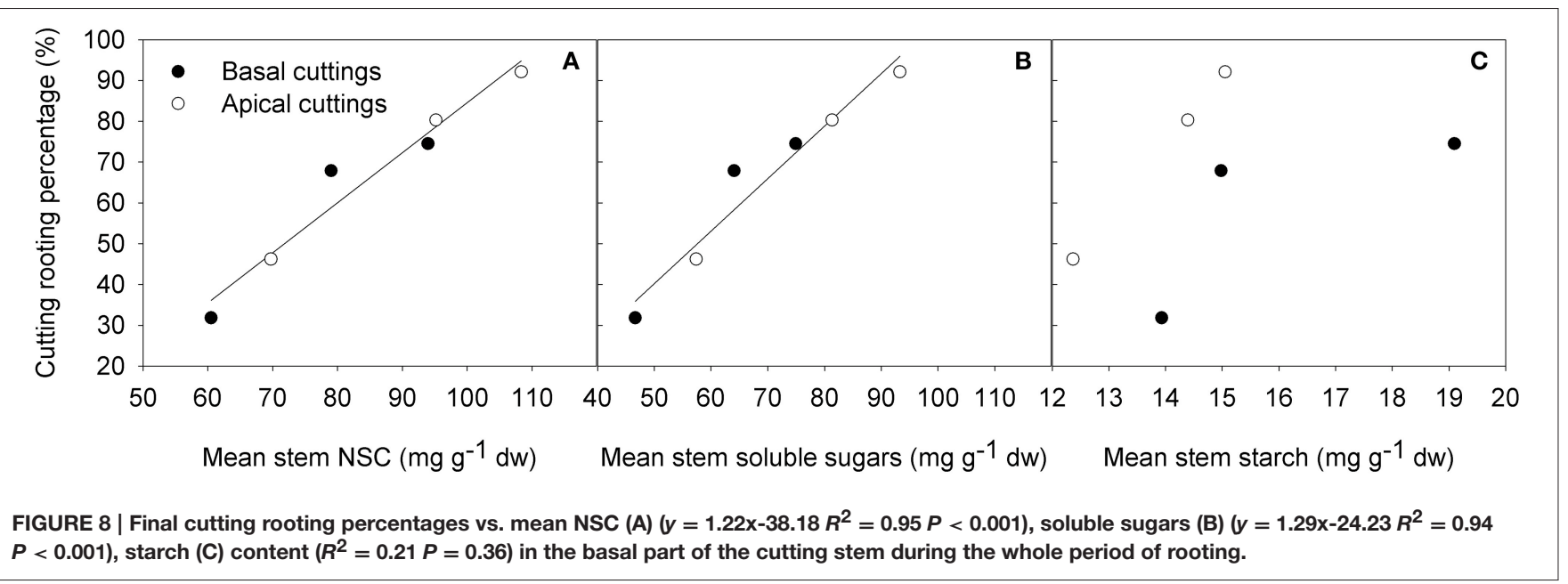

TABLE 3 | Relative frequencies of plant mortality measured at March 31st 2015.

\begin{tabular}{|c|c|c|c|c|c|c|c|c|}
\hline \multirow{2}{*}{$\begin{array}{l}\text { Treatment } \\
\text { Control }\end{array}$} & \multirow{2}{*}{$\begin{array}{l}\text { Cutting type } \\
\text { Apical }\end{array}$} & \multirow{2}{*}{$\begin{array}{l}\text { Rooting quality } \\
\text { Well-rooted }\end{array}$} & \multicolumn{6}{|c|}{ Plant mortality } \\
\hline & & & $27.7 \%$ & $b$ & $30.6 \%$ & $b$ & $33.9 \%$ & a \\
\hline & & Poorly rooted & $37.5 \%$ & a & & & & \\
\hline & Basal & Well-rooted & $35.3 \%$ & $b$ & $38.9 \%$ & a & & \\
\hline & & Poorly rooted & $50.0 \%$ & $a$ & & & & \\
\hline & Basal & Well-rooted & $21.7 \%$ & $\mathrm{~b}$ & $27.1 \%$ & a & & \\
\hline & & Poorly rooted & $34.7 \%$ & $\mathrm{a}$ & & & & \\
\hline \multirow[t]{2}{*}{ Shaded } & Apical & Well-rooted & $28.4 \%$ & $b$ & $30.6 \%$ & $b$ & $36.4 \%$ & $b$ \\
\hline & & Poorly rooted & $34.0 \%$ & $\mathrm{a}$ & & & & \\
\hline
\end{tabular}

Relative frequencies with different letters are different per $P=0.05\left(x^{2}\right.$-test).

cause leaf desiccation without increasing leaf photosynthesis. Optimization of mist apparatus spray intervals can help to counterbalance undesired VPD increase caused by greater light regimes.

In conclusion, in hazelnut leafy cuttings, rooting appear to be closely related to carbohydrate, in particular soluble sugars, content in cutting stems during the rooting process. Cutting carbohydrate status is positively influenced by leaf photosynthesis during rooting. Moderate light regimes (below of light saturation point) of leafy cuttings can contribute to improve photosynthetic activity of leafy cuttings. Collection of cuttings from different part of the mother shoots influenced rooting percentage and this appear to be related to the lower capability of cuttings from shoot base of concentrating soluble sugars in the cutting stem during rooting. Finally, cutting rooting percentage and quality can be enhanced by optimization of light environment during rooting.

\section{AUTHOR CONTRIBUTIONS}

ST and DF conceived and planned the study. ST and DF carried out the experiment, analyzed the data. ST wrote the first draft of the manuscript. AP, SP, and DF helped in the analysis of the data, revised, and edited the manuscript, and obtained funds to support the project.

\section{ACKNOWLEDGMENTS}

We thank the three reviewers who improved with their comments and suggestions the manuscript. 


\section{REFERENCES}

Aminah, H., McP Dick, J., and Grace, J. (1997). Influence of irradiance on water relations and carbon flux during rooting of Shorea leprosula leafy stem cuttings. Tree Phys. 17, 445-452. doi: 10.1093/treephys/17.7.445

Brinker, M. L., van Zyl, L., Liu, W., Craig, D., Sederoff, R. R., Clapham, D. H., et al. (2004). Microarray analyses of gene expression during adventitious root development in Pinus contorta. Plant Phys. 135, 1526-1539. doi: 10.1104/pp.103.032235

Chow, P. S., and Landhäusser, S. M. (2004). A method for routine measurements of total sugar and starch content in woody plant tissues. Tree Physiol. 24, 1129-1136. doi: 10.1093/treephys/24.10.1129

Contessa, C., Valentini, N., and Botta, R. (2011). Decreasing the concentration of IBA or combination with ethylene inhibitors improve bud retention in semihardwood cuttings of hazelnut cultivar "Tonda Gentile delle Langhe." Sci. Hortic. 131, 103-106. doi: 10.1016/j.scienta.2011.09.029

Cristofori, V., Rouphael, Y., and Rugini, E. (2010). Collection time, cutting age, IBA and putrescine effects on root formation in Corylus avellana L. cuttings. Sci. Hortic. 124, 189-194. doi: 10.1016/j.scienta.2009.12.034

Currey, C. J., Hutchinson, V. A., and Lopez, R. G. (2012). Growth, morphology, and quality of rooted cuttings of several herbaceous annual bedding plants are influenced by photosynthetic daily light integral during root development. Hortscience 47, 25-30.

Davis, T. D. (1988). "Photosynthesis during adventitious rooting," in Adventitious Root Formation in Cuttings, eds T. D. Davis, B. E. Haising, and N. Sankhla (Portland, OR: Dioscorides Press), 79-87.

Davis, T. D., and Potter, J. R. (1981). Current photosyntate as a limiting factor in adventitious root formation in leafy pea cuttings. J. Am. Soc. Hortic. Sci. 106, $278-282$.

DeKlerk, G. J., van der Krieken, W., and DeJong, J. C. (1999). The formation of adventitious roots: new concepts, new possibilities. In Vitro Cell Dev. Biol. Plant 35, 189-199. doi: 10.1007/s11627-999-0076-z

Druege, U., Zerche, S., and Kadner, R. (2004). Nitrogen- and storage-affected carbohydrate partitioning in high-light-adapted Pelargonium cuttings in relation to survival and adventitious root formation under low light. Ann. Bot. 94, 831-842. doi: 10.1093/aob/mch210

Fordham, M. C., Harrison-Murray, R. S., Knight, L., and Clay, C. M. (2001). Decline in stomatal response to leaf water deficit in corylus maxima cuttings. Tree Physiol. 21, 489-496. doi: 10.1093/treephys/21.8.489

Grange, R. I., and Loach, K. (1985). The effect of light on the rooting of leafy cuttings. Sci. Hortic. 27, 105-111. doi: 10.1016/0304-4238(85)90060-3

Haissig, B. E. (1989). Carbohydrate relations during propagation of cuttings from sexually mature Pinus banksiana trees. Tree Physiol. 5, 319-328. doi: 10.1093/treephys/5.3.319

Hansen, J. (1975). Light dependent promotion and inhibition of Adventitious root formation by Gibberellic Acid. Planta 123, 203-205. doi: 10.1007/BF00383871

Hartmann, H. T., and Brooks, R. M. (1958). Propagation of Stockton Morello cherry rootstock by softwood cuttings under mist sprays. Proc. Am. Soc. Hortic. Sci. 71, 127-134.

Hartmann, H. T., and Kester, D. E. (1983). Plant Propagation Principles and Practices, 4th Edn. Upper Saddle River, NJ: Prentice Hall.

Klopotek, Y., George, E., Druege, U., and Klaering, H. P. (2012). Carbon assimilation of petunia cuttings in a non-disturbed rooting environment: response to environmental key factors and adventitious root formation. Sci. Hortic. 145, 118-126. doi: 10.1016/j.scienta.2012.08.004

Legué, V., Rigal, A., and Bhalerao, R. P. (2014). Adventitious root formation in tree species: involvement of transcription factors. Phys. Plant 151, 192-198. doi: $10.1111 / \mathrm{ppl} .12197$

Loach, K. (1979). Mist propagation: past, present and future. Proc. Am. Soc. Hortic. Sci. 29, 216-229.
Loach, K., and Gay, A. P. (1979). The light requirement for propagating hardy ornamental species from leafy cuttings. Sci. Hortic. 10, 217-230. doi: 10.1016/0304-4238(79)90077-3

Loewus, F. A. (1952). Improvement in Anthrone Method for determination of carbohydrates. Anal. Chem. 24, 219-219. doi: 10.1021/ac60061a050

Lopez, R. G., and Runkle, E. S. (2008). Photosynthetic daily light integral during propagation influences rooting and growth of cuttings and subsequent development of new guinea impatiens and petunia. Hortscience 43, 2052-2059.

McCutchan, H., and Shackel, K. A. (1992). Stem-water potential as a sensitive indicator of water stress in prune trees (Prunus domestica L. cv. French). J. Am. Soc. Hortic. Sci. 117, 607-611.

Monteith, J. L., and Unsworth, M. H. (1990). Principles of Envirionmental Physics, 2nd Edn. New York, NY: Edward Arnold. 53-54.

Morris, D. L. (1948). Quantitative determination of carbohydrates with Drewood's Anthrone reagent. Science 107, 254-255. doi: 10.1126/science.107.2775.254

O'Rourke, F. L. (1944). Wood type and original position on shoot with reference to rooting in hardwood cuttings of blueberry. Proc. Am. Soc. Hortic. Sci. 45, 195-197.

Park, S. M., Won, E. J., Park, Y. G., and Jeong, B. R. (2011). Effects of node position, number of leaflets left, and light intensity during cutting propagation on rooting and subsequent growth of domestic roses. Hortic. Environ. Biotech. 52, 339-343. doi: 10.1007/s13580-011-0163-z

Saifuddin, M., Osman, N., and Rahman, M. M. (2013). Influence of different cutting positions and rooting hormones on root initiation and root-soil matrix of two tree species. Int. J. Agric. Biol. 15, 427?434.

Santelices, R., and Palfner, G. (2010). Controlled rhizogenesis and mycorrhization of hazelnut (Corylus avellana L.) cuttings with black truffle (Tuber melanosporum Vitt.). Chilean J. Agric. Res. 70, 204-212. doi: 10.4067/S071858392010000200003

Smalley, T. J., Dirr, M. A., Armitage, A. M., Wood, B. W., Teskey, R. O., and Severson, R. F. (1991). Photosynthesis, leaf water, carbohydrate, and hormone status during rooting of stem cuttings of Acer rubrum. J. Am. Soc. Hortic. Sci. 116, 1052-1057.

Stoutemyer, V. T., and Close, W. T. (1946). Rooting cuttings and germinating seeds under fluorescent and cold cathode light. Proc. Am. Soc. Hortic. Sci. 48, 309-325.

Svenson, S. E., Davies, F. T. Jr., and Duray, S. A. (1995). Gas exchange, water relations, and dry weight partitioning during root initiation and development of poinsettia cuttings. J. Am. Soc. Hortic. Sci. 120, 454-459.

Waxman, S. (1965). Propagation of blueberries under fluorescent light at various intensities. Proc. Int. Plant Propag. Soc. 15, 154-158.

Yue, D., and Margolis, H. A. (1993). Photosynthesis and dark respiration of black spruce cuttings during rooting in response to light and temperature. Can. J. For. Res. 23, 1150-1155. doi: 10.1139/x93-146

Zaczek, J. J., Heuser, C. W., Steiner, K. C. Jr. (1997). Effect of shade levels and IBA during the rooting of eight tree taxa. J. Environ. Hortic. 15, 56-60.

Zobolo, A. M. (2010). Effect of temperature, light intensity and growth regulators on propagation of Ansellia Africana from cuttings. Afr. J. Biotech. 9, 5566-5574.

Conflict of Interest Statement: The authors declare that the research was conducted in the absence of any commercial or financial relationships that could be construed as a potential conflict of interest.

Copyright (C) 2015 Tombesi, Palliotti, Poni and Farinelli. This is an open-access article distributed under the terms of the Creative Commons Attribution License (CC BY). The use, distribution or reproduction in other forums is permitted, provided the original author(s) or licensor are credited and that the original publication in this journal is cited, in accordance with accepted academic practice. No use, distribution or reproduction is permitted which does not comply with these terms. 